\title{
The Use of Process Analysis and Simulation to Identify Paths to Improve the Operation of an Iron Ore Gravity Concentration Circuit
}

\author{
Maryam Sadeghi' ${ }^{1}$, Claude Bazin ${ }^{2}$ \\ ${ }^{1}$ Hatch Ltd., Montréal, QC, Canada \\ ${ }^{2}$ Department of Mining, Metallurgy and Materials Engineering, Laval University, Quebec, QC, Canada \\ Email: claude.bazin@gmn.ulaval.ca
}

How to cite this paper: Sadeghi, M. and Bazin, C. (2020) The Use of Process Analysis and Simulation to Identify Paths to Improve the Operation of an Iron Ore Gravity Concentration Circuit. Advances in Chemical Engineering and Science, 10, 149-170. https://doi.org/10.4236/aces.2020.103011

Received: April 30, 2020

Accepted: June 6, 2020

Published: June 9, 2020

Copyright $\odot 2020$ by author(s) and Scientific Research Publishing Inc. This work is licensed under the Creative Commons Attribution International License (CC BY 4.0).

http://creativecommons.org/licenses/by/4.0/

\section{(c) (i) Open Access}

\begin{abstract}
The processing of iron ore to recover the valuable iron oxide minerals is commonly carried out using spiral concentrators that separate valuable minerals from non-valuable ones on the basis of the specific gravity of minerals. This paper shows that the analysis of the operation of spirals should not only focus on the minerals (as it is usually the case), but should also consider the particle size of these minerals. Indeed, the sampling of two industrial iron ore circuits and the data processing of the resulting measurements show that unexpectedly about $10 \%$ of the coarse heavy iron oxide minerals are not recovered by the spirals of the two circuits. Tests conducted by an independent research center confirm this plant observation. The pilot plant tests also show that the wash water flowrate addition may adversely affect the recovery of coarse heavy mineral particles. A mathematical model for the spiral was implemented into a simulator for an iron ore gravity concentration circuit. The simulator shows a potential $0.7 \%$ increase of iron recovery by simply changing the strategy used to distribute the wash water between the rougher and the cleaner/recleaner spirals of the circuit. The simulator also shows that the introduction of a hydraulic classifier into the gravity concentration circuit yields a marginal improvement to the performances of the circuit.
\end{abstract}

\section{Keywords}

Iron Ore, Gravity Separation, Spiral Concentrators, Hematite, Hydraulic Classifier, Particle Size, Partition Curves 


\section{Introduction}

The valorization of iron ores is commonly carried out by gravity and/or magnetic separation depending upon the nature of the valuable iron oxide minerals. Coarse hematite $\left(\mathrm{Fe}_{2} \mathrm{O}_{3}\right)$ is recovered by gravity separation while fine magnetite $\left(\mathrm{Fe}_{3} \mathrm{O}_{4}\right)$ is separated from gangue minerals by magnetic separators. Some iron ore processing plants [1] combine the two approaches to produce the iron oxide concentrate destined to the steel producers. This paper deals with the gravity concentration of iron ores.

Canadian processors recover coarse hematite using spiral concentrators. Spiral concentrators have been used in the industry for more than 70 years [2]. In spite of this long life, the literature on spiral concentrators is fairly limited if one compares it to the literature dealing with the flotation process. However, there is a significant incentive for studying the operation of spiral concentrators. Indeed, iron ore plants usually process on a daily basis more than 100,000 $t$ [1] of ore through spirals. For such throughput, a $0.5 \%$ improvement in the recovery of iron minerals can yield additional revenues of several hundred thousand dollars per year. The technical papers dealing with spirals are either fundamental or empirical. The fundamental papers describe the behavior of one particle in the spiral using an analysis of the forces applied to that particle [3]. It should also be indicated that none of these papers reported the introduction of such fundamental model into a simulator for a gravity separation circuit. The other class of papers dealing with spirals considers the spiral as a black box [4] and relates the recovery of iron rather than that of the minerals that carry iron to the spiral input variables (namely, the openings of the concentrate cutters, the spiral slurry feed rate and density...). Srivastava et al. [5] incorporated such model into a process simulator without attempting to use the model to find ways to improve the circuit performances. The main weakness of these approaches is related to the fact that the effect of particle size is seldom incorporated into the model.

This paper shows that the operations of spiral should not only be analyzed in terms of recovery of the valuable minerals and concentrate grade as it is usually done, but that strategic information lies in the behavior of mineral particles as a function of their size. The analysis of the effect of particle size, as it is done here, provides ground to propose operating strategies to improve the performance of a gravity concentration circuit. A circuit simulator is used to explore some of these strategies.

The paper is divided into 3 sections. The first section recalls the basic concepts of spiral operation in order to standardize the vocabulary. The second section shows that for two Canadian concentrators not only fine iron oxide particles are not recovered by spirals but unexpectedly coarse iron oxide particles are also lost in a gravity circuit using spiral concentrators. The third section illustrates the application of computer simulation to study options to reduce the losses of coarse iron oxide particles and increase the iron recovery of a gravity concentration plant. 


\section{Spiral Concentrators and Iron Ore Processing Circuit}

\subsection{Operation of a Spiral Concentrator}

A spiral concentrator is shown in Figure 1(a). It is a twisted channel around a vertical axis. The spiral is fed by a slurry of water and ground ore particles that enters the top of the spiral (see Figure 1(b)). As the slurry flows down the spiral, heavy particles move toward the inner part of the spiral trough, while water and

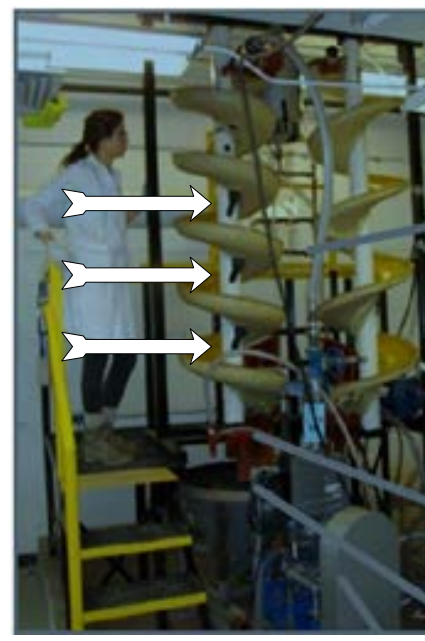

(a)

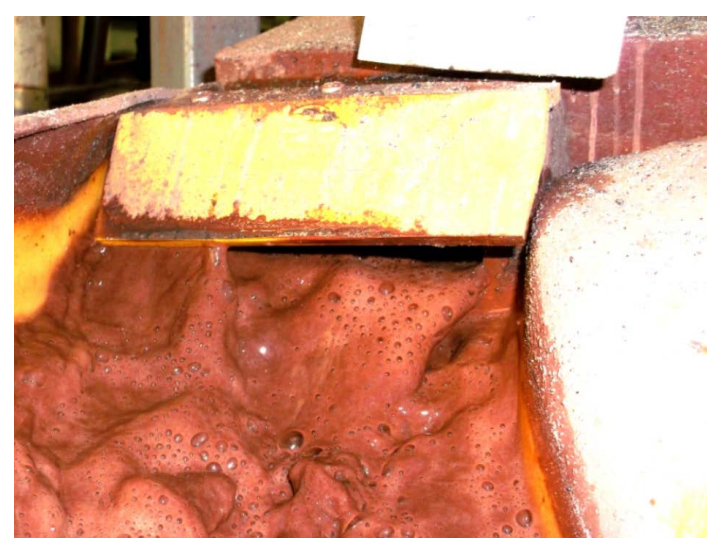

(b)

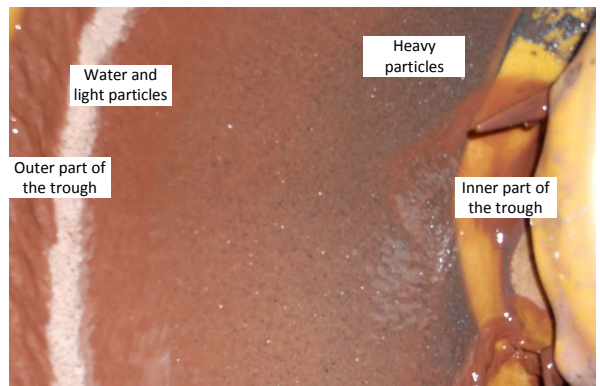

(c)

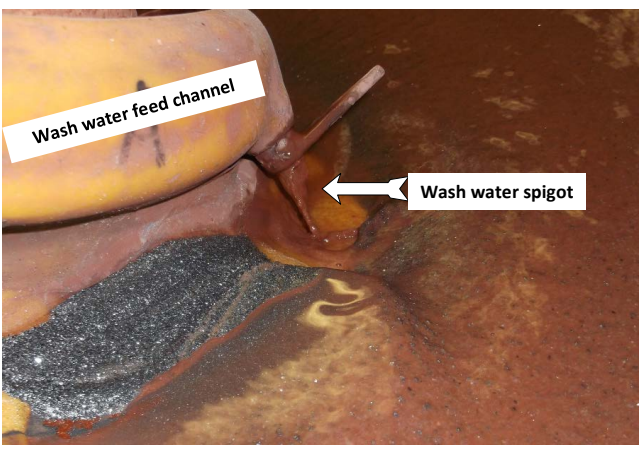

(e)

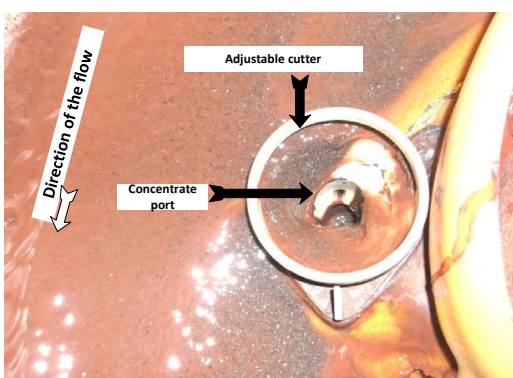

(d)

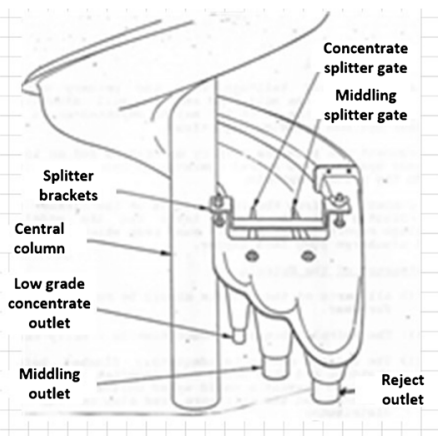

(f)

Figure 1. Spiral concentrator. (a) Spiral with the concentrate ports connected to the central tube; (b) Slurry entering the top of the spiral; (c) Separation of light and heavy particles after two turns; (d) Concentrate ports and adjustable cutter to recover the slurry flowing in the inner part of the spiral trough; (e) A wash water addition to the inner part of a spiral trough; (f) Adjustable splitters at the discharge of a spiral [8]. 
light particles are swept to the outer part of the trough as illustrated in the photo of Figure 1(c) taken from a spiral used for the separation of valuable heavy hematite $\left(\mathrm{Fe}_{2} \mathrm{O}_{3}\right)$ from light quartz $\left(\mathrm{SiO}_{2}\right)$ gangue particles. Wash water is added into the inner part of the spiral [6] [7] to repulp settled heavy particles as in Figure 1(d) and to wash unwanted light particles away from the inner stream flow [8] that should be occupied by heavy particles. Traps or concentrate ports located at various heights of the spiral (usually every 1.5 turn) on the inner part of the trough collect the flow of heavy particles. The collected material from a concentrate port is directed toward the central post of the spiral (see white arrow in Figure 1(a)) to join the material collected by the other ports to give the stream of heavy minerals or concentrate if the heavy minerals are the valuable substance as it is the case for iron oxide. An adjustable cutter (see Figure 1(d)) installed on each concentrate port controls the width of the flowing slurry stream that is collected by the concentrate port [8]. Mishra and Tripaty [9] reported a study on the effect of the cutter openings on the spiral operation. The slurry that is not collected by the concentrate ports flows down to the last turn of the spiral where it discharges through adjustable splitters (see Figure 1(f)) that divide the slurry into low grade concentrate, middlings and reject streams.

The manipulated variables used to control the operation of spirals are:

- The flow rate of wash water that is increased to increase the concentration of heavy minerals in the concentrate or stream of heavy minerals, usually at the expenses of recovery of heavy minerals in the concentrate. Action on the wash water is the preferred way of controlling the spiral operation. The wash water addition also repulp the settled heavy minerals as in Figure 1(e);

- The position of the splitter gates at the discharge of the spiral (Figure 1(f));

- The opening of the cutters on the concentrate ports. This action is seldom used considering that it has to be manually applied for each spiral of a plant that may operate more than one thousand spirals.

\subsection{Iron Ore Processing Circuit}

The typical gravity concentration circuit used by Canadian iron ore processors is shown in Figure 2. For the two Canadian iron ore processing plants considered in this paper, hematite $\left(\mathrm{Fe}_{2} \mathrm{O}_{3}\right)$ and quartz $\left(\mathrm{SiO}_{2}\right)$ make $99 \%$ of the processed ore. The ore that assays $33 \% \mathrm{Fe}$ is firstly ground to liberate the hematite [2] and the ground ore is fed with water into a battery of more than 100 parallel rougher spirals (see Figure 2), whose concentrate is cleaned twice to give an iron oxide concentrate assaying more than $66 \% \mathrm{Fe}$. The typical iron ore upgrading from the rougher spirals to the final concentrate is shown in Figure 2. Plants typically target a final concentrate assaying $66 \% \mathrm{Fe}$ so it can be sold to steel producers. The production of an iron oxide concentrate with an iron content above $66 \%$, is usually at the expenses of recovery of salable material, measured by the weight recovery $\left(R_{W}\right)$ given by: 

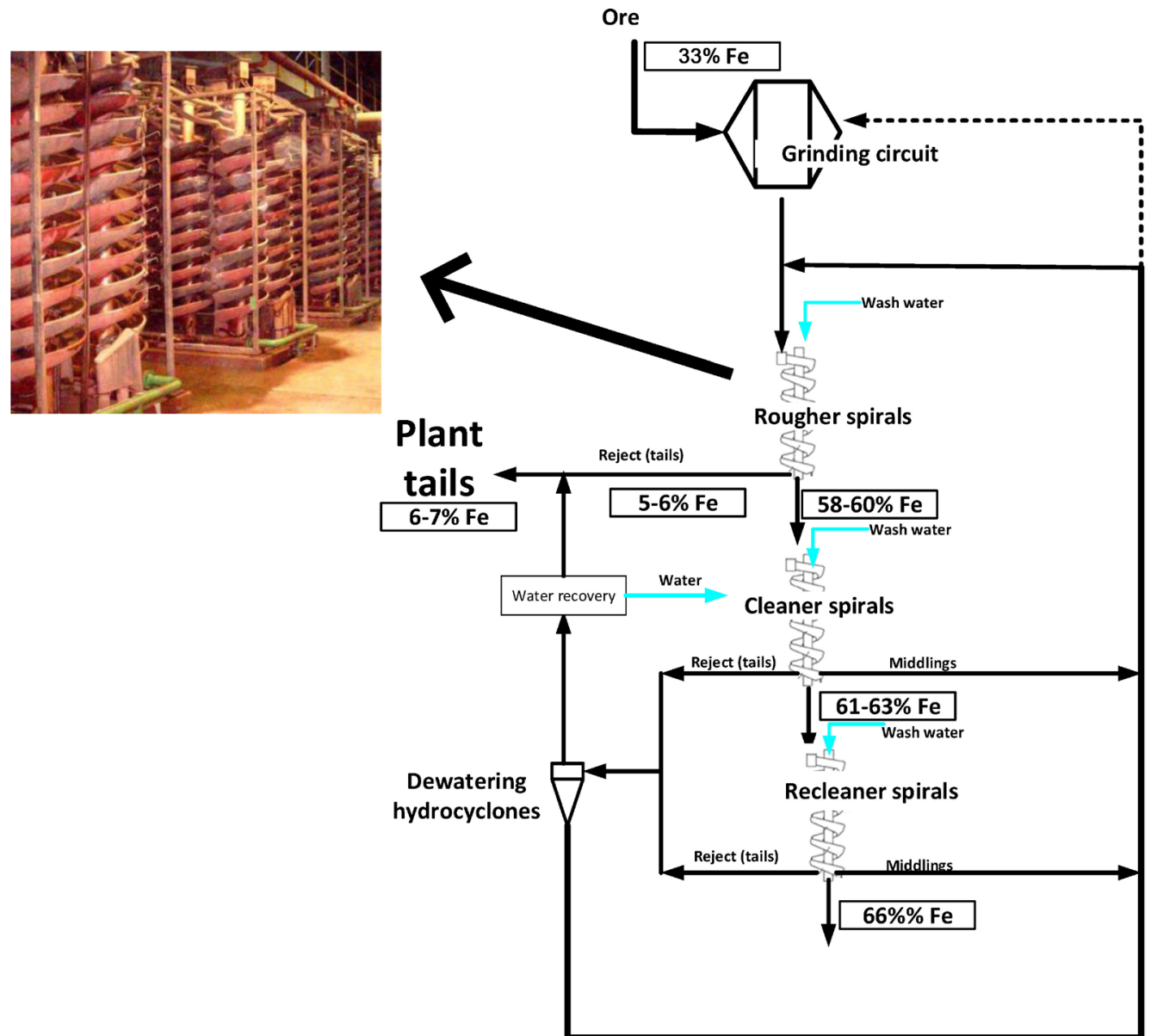

Figure 2. Gravity concentration circuit for iron ore.

$$
R_{W}=100 \times \frac{\text { Tons of concentrate produced }}{\text { Tons of ore fed in the separation circuit }}
$$

The weight recovery typically ranges between $34 \%$ and $36 \%$, and should be maximized while maintaining the iron content of the concentrate above or equal to $66 \%$.

The splitters at the discharge (see Figure 1(f)) of the cleaner and recleaner spirals are set to produce streams of reject and middling. The cleaner/recleaner reject streams feed dewatering hydrocyclones, while the middlings streams are either returned to the rougher spirals or to the grinding mill (see Figure 2).

\section{Analysis of the Operation of Spiral Concentrators of Two Iron Ore Processing Plants}

The data used for the analysis presented in this section come from sampling campaigns conducted in the ArcelorMittal mount Wright concentrator in northern Quebec [10] and in the former Cliffs Natural Ressources Bloom Lake concentrator now operated by Champion Iron under the name of Minerai de Fer Quebec [11] (https://mineraiferquebec.com). Data also come from tests conducted at the COREM research facilities in Quebec City (https://www.corem.qc.ca/). 


\subsection{Observed Partition Curves for Industrial Spirals}

The gravity circuits of the two studied iron ore concentrators are similar to the circuit shown in Figure 2. Detailed sampling campaigns were conducted on the two circuits [10]. Each stream of the circuits was sampled with the samples processed to obtain the following measurements:

- Slurry \% solids;

- Ore chemical composition (\% Fe and $\left.\% \mathrm{SiO}_{2}\right)$;

- Ore size distribution (from $2 \mathrm{~mm}$ down to $0.037 \mathrm{~mm}$ );

- Chemical composition (\% $\mathrm{Fe}$ and $\left.\% \mathrm{SiO}_{2}\right)$ of the ore within the size intervals.

The data were balanced using BILMAT [12] in order to have the mass flowrates of each species in every stream of the circuit. The balanced results are used to calculate the partition factors for iron and silica in the spirals of the circuit. The partition factor $Y_{i ; m}$ gives the proportion of hematite or quartz (index m) within a size interval $i$ (index $i)$ of the ore feeding a spiral that reports to the concentrate stream of that spiral. It is calculated from the balanced data using:

$$
Y_{i ; m}=\frac{W_{C} g_{C ; i} x_{C ; i ; m}}{W_{F} g_{F ; i} x_{F ; i ; m}}
$$

The variable $W$ stands for a solid flow rate, while $\mathrm{g}_{\mathrm{i}}$ indicates the weight retained within size interval $i$ and $x_{i ; m}$ is the mass fraction of species $\mathrm{m}\left(\mathrm{Fe}\right.$ or $\left.\mathrm{SiO}_{2}\right)$ within size interval $i$. The subscripts $\mathrm{F}$ and $\mathrm{C}$ indicate respectively the feed and concentrate streams of the spiral. The partition factors are usually plotted as a function of the particle size to obtain the partition curves. The calculated partition curves for the spirals of the two studied circuits are shown in Figures 3-8. The average partition curves of 9 sampling campaigns are shown as full lines in Figures 3-8 with the corresponding 95\% confidence interval as dashed lines. Results systematically show that the recovery of fine iron $(<0.040 \mathrm{~mm})$ ranges from $40 \%$ to $60 \%$. This result was expected as spirals are not reputed to recover fine particles [13]. The observed, but unexpected behavior is the recovery of coarse iron $(+1.0 \mathrm{~mm})$ that after reaching a plateau falls below the foreseen $100 \%$ recovery for a gravity concentrator.

Indeed for a gravity concentrator it is expected to observe recovery of heavy minerals reaching $100 \%$ with increasing particle size as it is the case for the partition curves shown in Figure 9 for a hydraulic classifier. The observed behavior of coarse hematite in the spiral circuit of ArcelorMittal and Bloom Lake (Figures 3-8) was initially attributed to insufficient liberation of hematite, resulting in particles of intermediate density, made of hematite and quartz as illustrated in Figure 10. However the partition curves for quartz do not show the increased recovery for coarse quartz particles that could have confirmed the liberation hypothesis. Micrographies of polished sections of the rejects of the rougher spirals are reproduced in Figure 11, and show the presence of coarse liberated hematite particles in this stream which further refutes the insufficient liberation hypothesis. In order to confirm that the behavior of coarse hematite particles is 


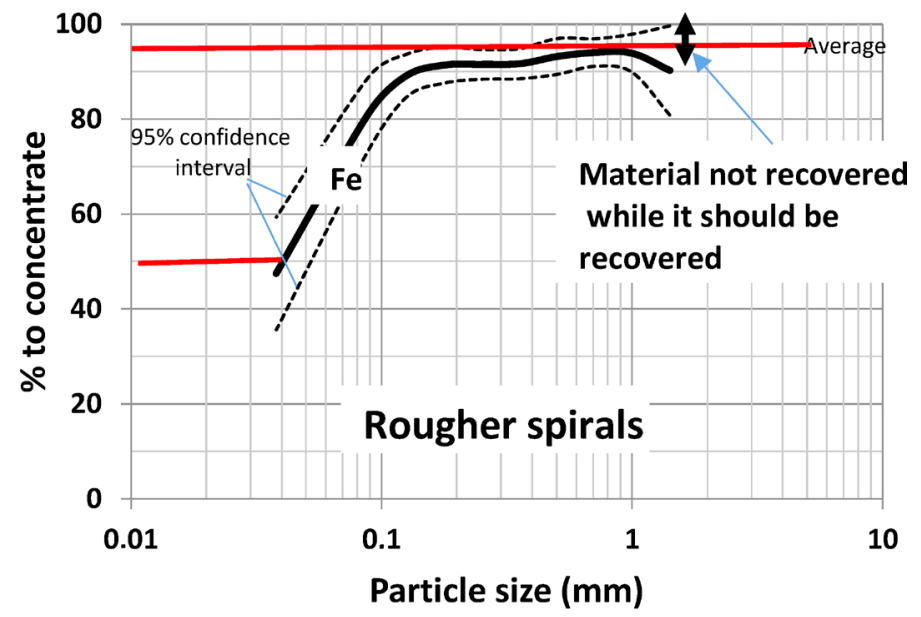

Figure 3. Partition curves for Fe minerals for the rougher spirals of the Arcelor Mittal Mount Wright concentrator (Full line: average of 9 sampling campaigns; dashed lines: 95\% confidence intervals).

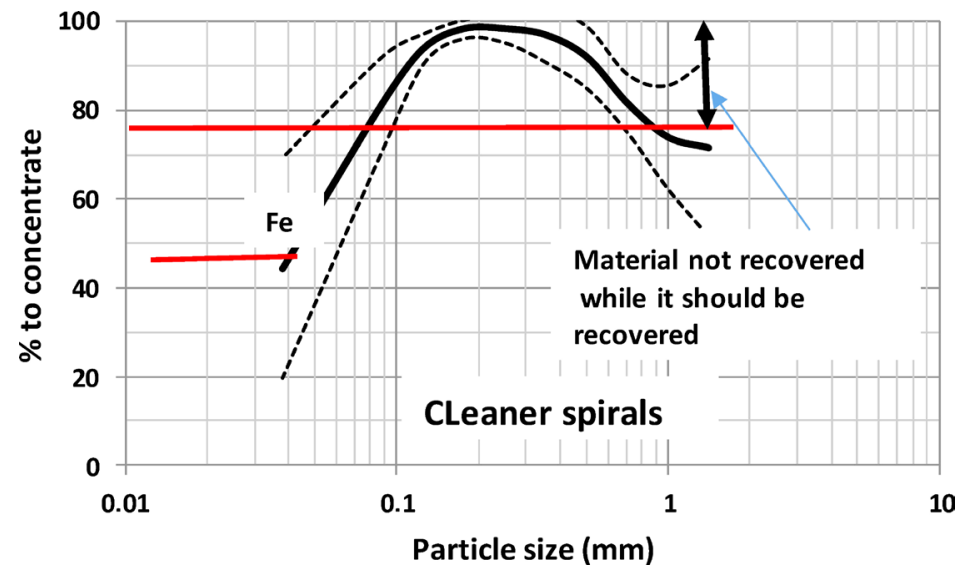

Figure 4. Partition curves for Fe minerals for the cleaner spirals of the Arcelor Mittal Mount Wright concentrator (Full line: average of 9 sampling campaigns; dashed lines: $95 \%$ confidence intervals).

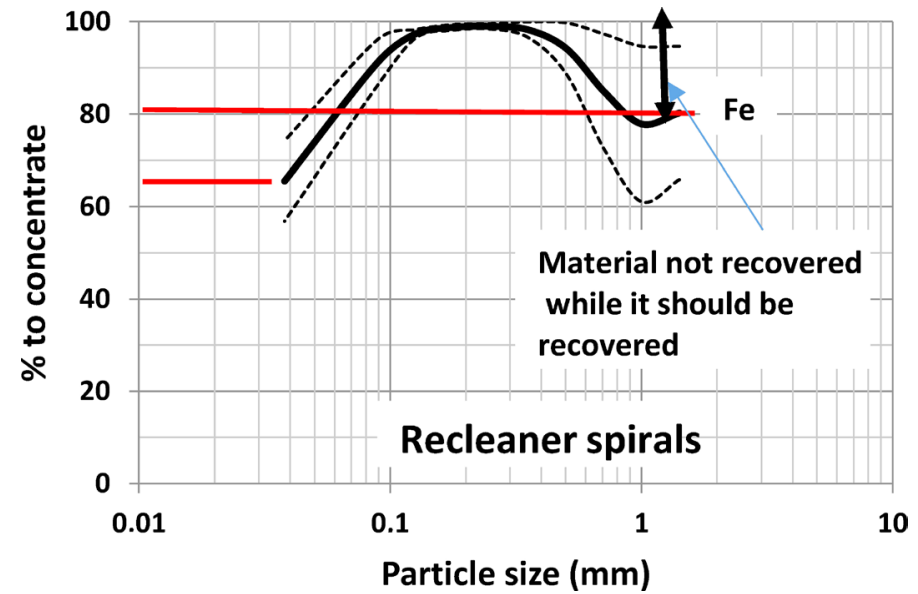

Figure 5. Partition curves for $\mathrm{Fe}$ and $\mathrm{SiO}_{2}$ for the re-cleaner spirals of the Arcelor Mittal Mount Wright concentrator (Full line: average of 9 sampling campaigns; dashed lines: $95 \%$ confidence intervals). 


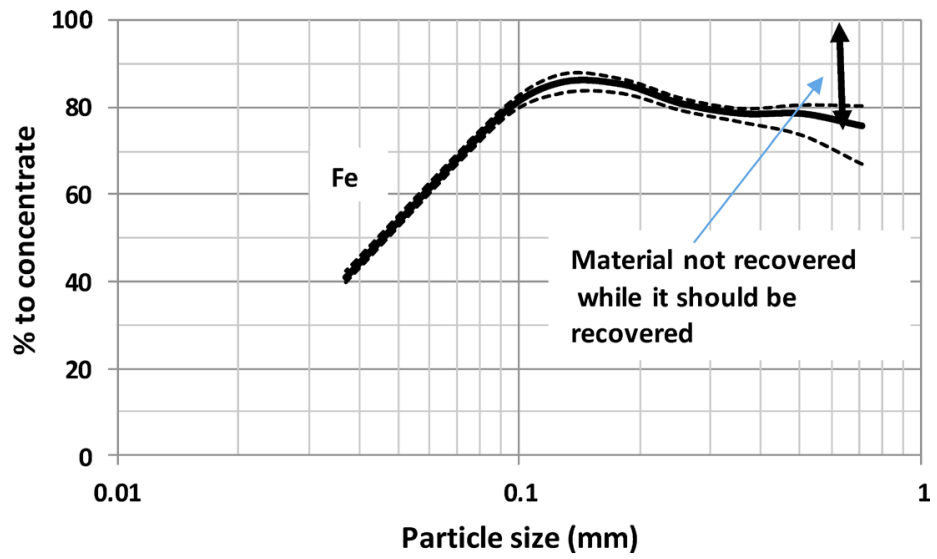

Figure 6. Partition curves for Fe minerals for the rougher spirals of the Minerai de fer Quebec, Lac Bloom iron ore concentrator (Full line: average of 9 sampling campaigns; dashed lines $95 \%$ confidence intervals).

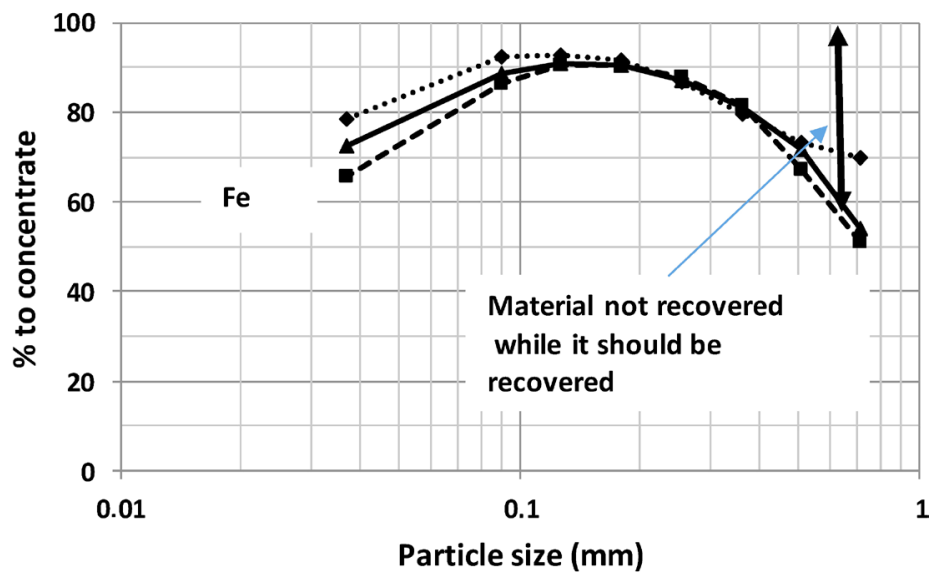

Figure 7. Partition curves for Fe minerals for the cleaner spirals of the Minerai de fer Quebec, Lac Bloom iron ore concentrator (Full line: average of 9 sampling campaigns; dashed lines $95 \%$ confidence intervals).

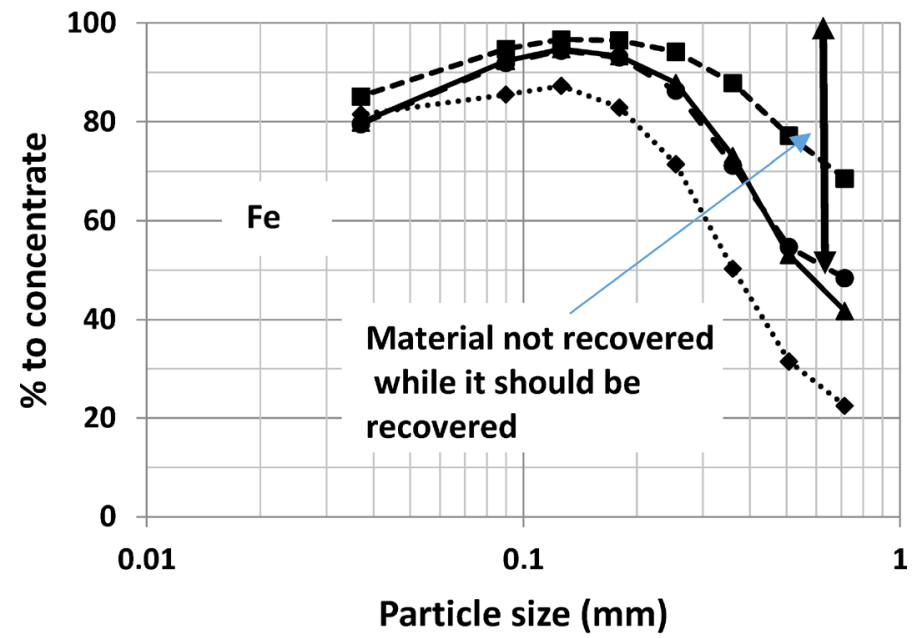

Figure 8. Partition curves for $\mathrm{Fe}$ and $\mathrm{SiO}_{2}$ for the recleaner spirals of the Minerai de fer Quebec, Lac Bloom iron ore concentrator (Full line: average of 9 sampling campaigns; dashed lines $95 \%$ confidence intervals. 


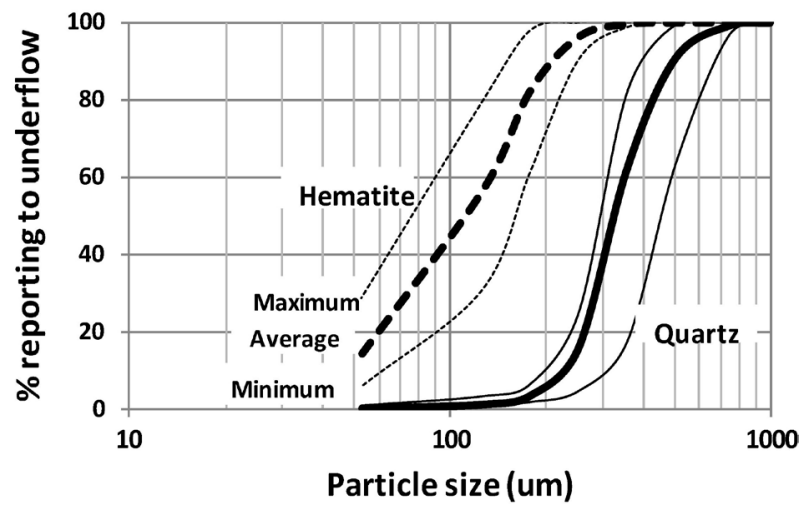

Figure 9. Observed partition curves for gravity concentrators [14].

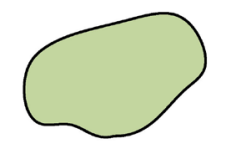

Liberated hematite SG=5.07

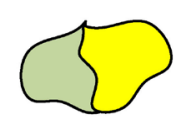

Unliberated hematite/ quartz

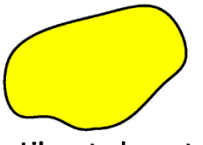

Liberated quartz SG=2.7

Figure 10. Concept of unliberated hematite particles made of quartz and hematite with intermediate specific gravity.

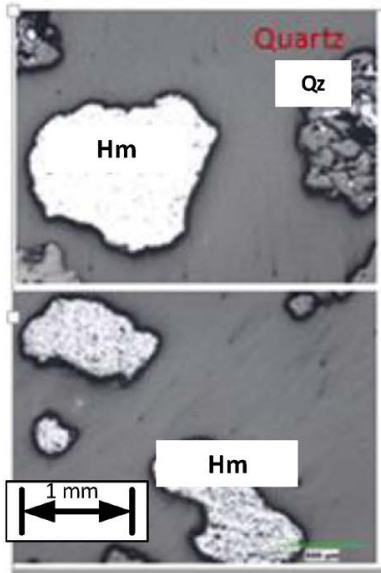

$+1.2 \mathrm{~mm}$

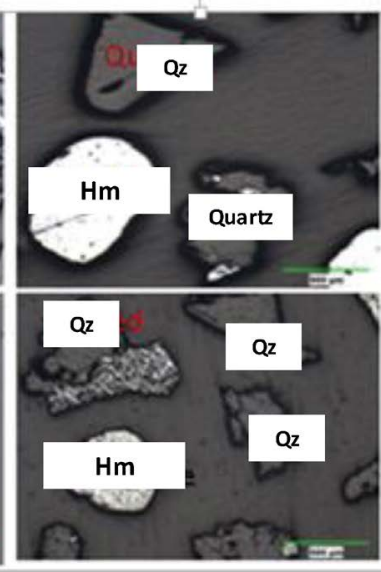

$-1.2+0.85 \mathrm{~mm}$

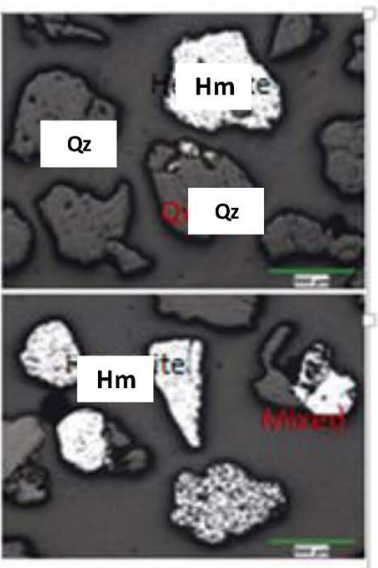

$-0.85+0.6 \mathrm{~mm}$

Figure 11. Polished sections of the coarse fractions of the reject of the rougher spiral showing coarse liberated hematite particles (Hm: Hematite; Qz: Quartz).

not due to the effect of an industrial operating variable or practice, experiments were conducted under well controlled conditions using a test spiral at COREM [6] in Quebec City. An iron ore sample from the Arcelor-Mittal Mount Wright mine was used for the tests conducted with the pilot plant spiral. Figure 12 shows the observed partition curves for hematite and silica. Results confirm that the recovery of coarse iron effectively falls below $100 \%$. It was found later that this recovery drop is due to the Bagnold force [15] whose action increases with increasing particle size. The Bagnold force finds its origin in the secondary current [16] and in the action of the wash water added into the spiral as shown by 
the partition curves observed for three levels of wash water addition reproduced in Figure 13.

\subsection{Discussion}

Since most of the plant rejects for the two studied iron ore concentration circuits come from the rougher spirals, iron losses mainly originate from these spirals as fine and coarse iron oxide minerals. The recovery of fine iron oxide minerals from that stream is possible via magnetic separators if the iron is under the form of magnetite $\left(\mathrm{Fe}_{3} \mathrm{O}_{4}\right)$, otherwise flotation may offer a potential way to recover the fine iron minerals from the rougher spirals tails. On the other hand, the recovery of coarse hematite could potentially be improved by adjusting the operating conditions of the rougher spirals or by the introduction into the circuit of equipment that can recover coarse hematite more efficiently than spirals.

As for the first option, a reduction of the wash water addition to the rougher spirals should reduce the losses of coarse iron as observed in Figure 13. However a

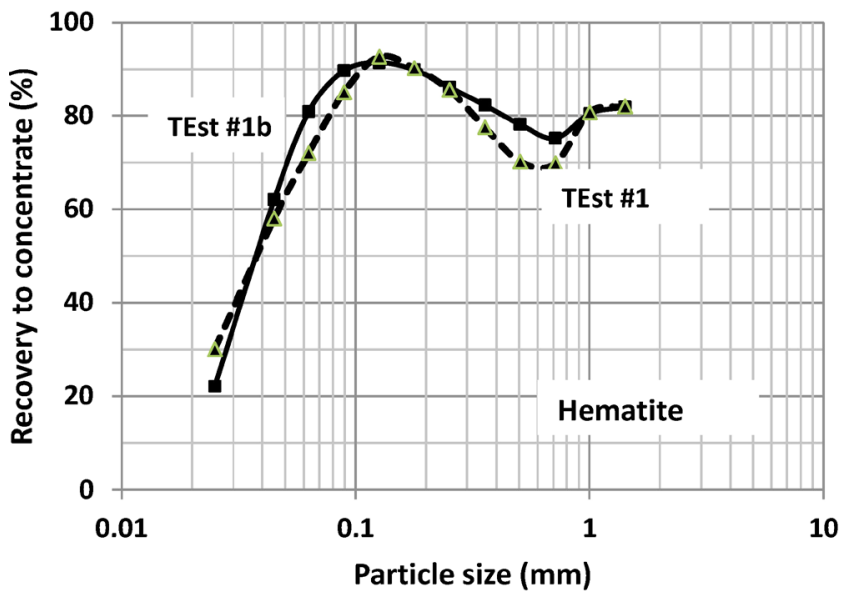

Hematite

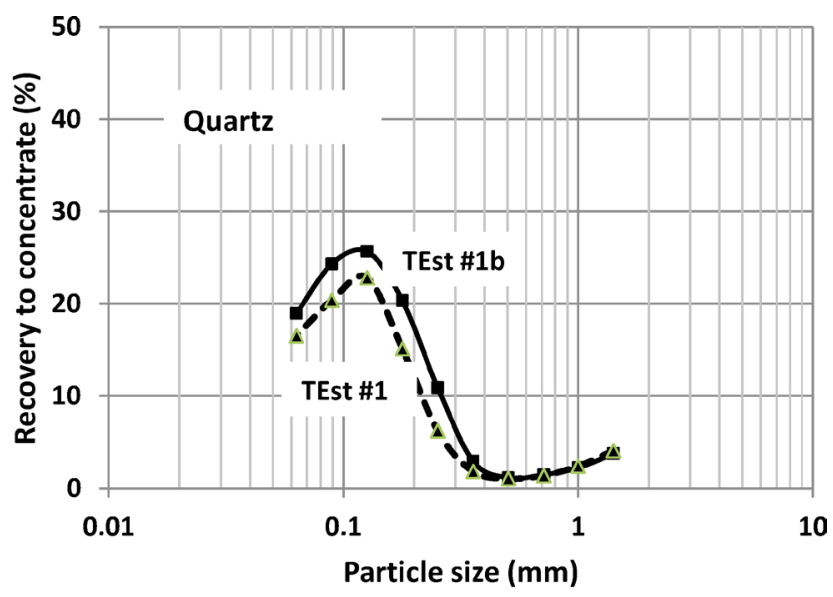

Quartz

Figure 12. Hematite partition curves obtained from two replicated tests on a pilot plant spiral at COREM [6].
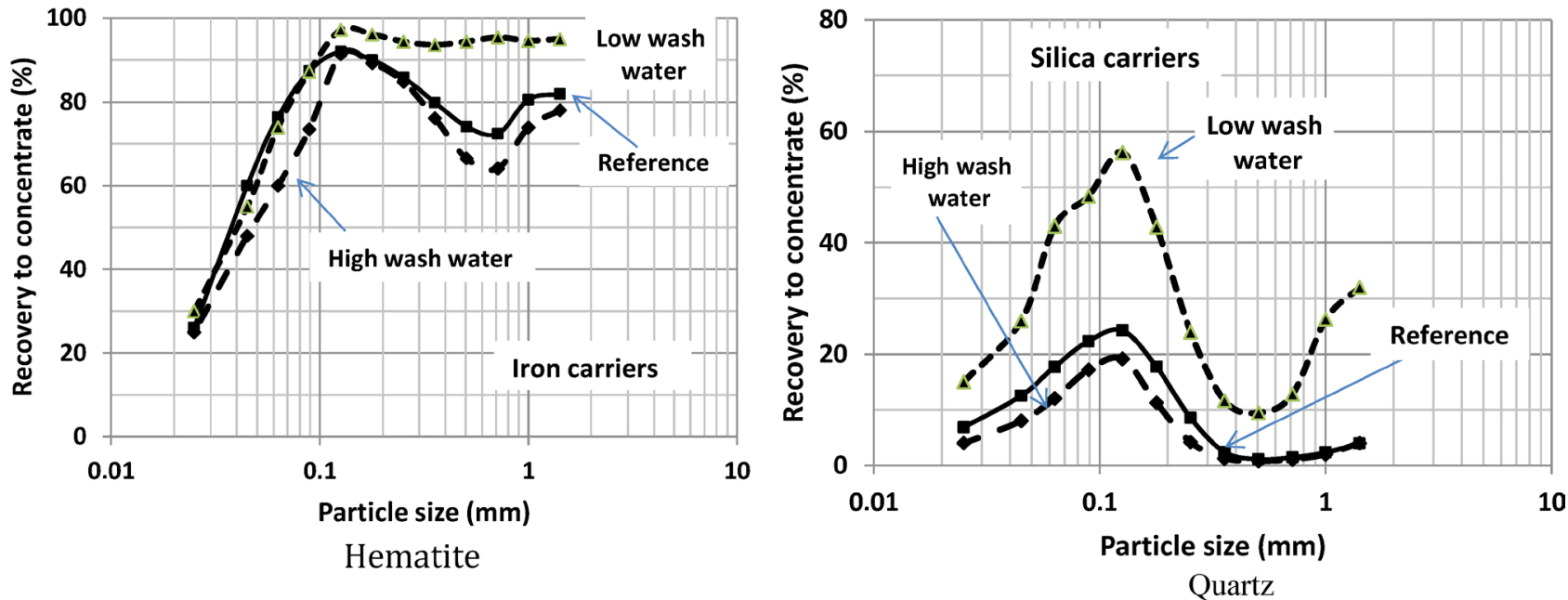

Figure 13. Effect of wash water on the recovery of coarse hematite in the concentrate of a test spiral [6]. 
decrease in the wash water addition will reduce the iron content of the rougher concentrate which may eventually cause the iron content of the final concentrate to fall below the target $66 \% \mathrm{Fe}$. This can be compensated by increasing the addition of wash water into the cleaner and recleaner spirals. This action will increase the final concentrate grade but may induce losses of coarse hematite to the middling streams that are returned to the rougher spirals for which the reduced wash water addition is favorable to the recovery of coarse iron minerals. Predicting the end effect of this strategy is difficult unless one uses a computer program to simulate the circuit.

The other option to improve the iron recovery is to replace the cleaner and re-cleaner spirals by an equipment that can separate iron oxide from quartz particles with minimum losses of coarse valuable minerals. Unlike the first option, this approach implies capital expenditures (Capex).

\section{Simulation}

Two simulation cases are presented in this section. The first case examines the potential of increasing the circuit recovery by adjusting-as discussed above-the wash water addition to the rougher, cleaner, re-cleaner spirals. There are no capital cost expenditures (Capex) associated with this option. The second case considers a modification to the process, and thus implies Capex. The objective of both simulation cases is to assess the potential increase of iron recovery in the circuit while maintaining the concentrate on the target grade.

\subsection{Simulation of a Change of Strategy to the Addition of Wash Water to Spirals}

A preliminary mathematical model for the spiral was developed [7] [10] and programmed into a simulator for a gravity circuit in order to assess the previous options before moving to full scale evaluation. The spiral model accepts changes to the wash water additions and to the opening of the discharge splitter (Figure $1(f)$ ). The input variables for the simulator are:

- The characteristics of the circuit feed, i.e.:

- The solid flow rate and slurry \% of solids;

- The concentration of hematite and quartz;

- The size distributions of hematite and quartz;

- The flowrate of wash water to the rougher, cleaner and re-cleaner spirals;

- The splitter position for each battery of spirals.

The Plitt's model [17] is used to simulate the dewatering hydrocyclones (Figure 2). A sequential approach is used to simulate the gravity concentration circuit of Figure 2. Using the circuit feed characteristics, the rougher spirals are first simulated to obtain the characteristics (mass flow rate, mineral size distributions) of the rougher concentrate. These data are used to simulate the operation of the cleaner spirals. The simulated characteristics of the cleaner concentrate are used to simulate the recleaner spirals. The simulated characteristics of 
the middlings from the cleaner-recleaner spirals are then returned to the rougher spirals for another simulation sequence and the process is repeated until convergence. The simulator is programmed in PASCAL in the Delphi Embarcadero $^{\mathrm{TM}}$ environment. Figure 14 shows a capture of the simulator interface screen.

The sequence of steps conducted to assess the previous idea is presented in Table 1 . The sequence starts by tuning the operating variables so that the simulation reproduces the nominal plant operation. The final concentrate assays $66.1 \% \mathrm{Fe}$ at a weight recovery of $34.4 \%$. The rougher concentrate assays $57.2 \%$ Fe. As discussed previously the first move to be carried out in the attempt to increase the weight recovery of the circuit is to reduce the wash water added to the rougher spirals in order to reduce the losses of coarse hematite. As anticipated the action causes a decrease of the rougher grade that falls to $56.8 \%$ (see Table 1 ) causing a decrease of the final concentrate grade to $65.8 \% \mathrm{Fe}$, but at higher weight recovery of $35.6 \%$ (see Table 1). To follow up with the proposed strategy, the wash water addition to the cleaner/recleaner spirals is increased to bring the final concentrate grade back on the $66 \%$ target. This action successfully increases the iron content of the final concentrate to $66.1 \% \mathrm{Fe}$ with a $35.1 \%$ weight recovery (see Table 1), showing that the proposed strategy is viable and deserves to be tested in the plant.

It is not said here that a full scale trial will give exactly the simulated results, however the simulation has provided a noise free environment to test ideas and to assess process responses, a task that may be risky to try in a plant that is

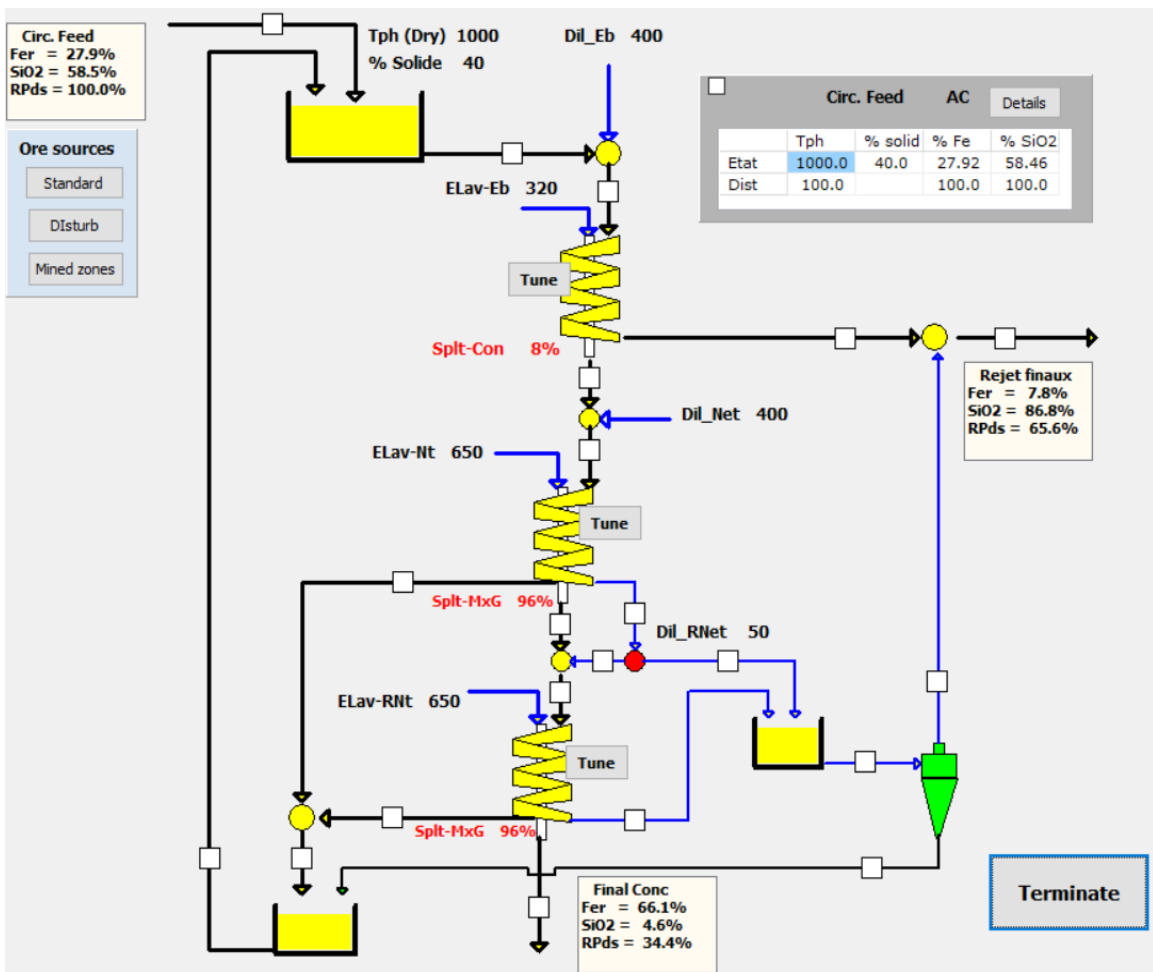

Figure 14. Interface of the gravity circuit simulator. 
Table 1. Steps of a simulation study to increase the weight recovery of the circuit shown in Figure 2.

\begin{tabular}{|c|c|}
\hline Performance indices and wash water flow rates & Conditions or actions \\
\hline Wash water to the rougher spirals: $320 \mathrm{~m}^{3} / \mathrm{h}$ & \multirow[t]{6}{*}{ Nominal conditions } \\
\hline Rougher concentrate: $57.2 \% \mathrm{Fe}$ & \\
\hline Wash water to the cleaner spirals: $650 \mathrm{~m}^{3} / \mathrm{h}$ & \\
\hline Wash water to the re-cleaner spirals: $650 \mathrm{~m}^{3} / \mathrm{h}$ & \\
\hline Final Concentrate: $66.1 \% \mathrm{Fe}$ & \\
\hline Weight recovery to final concentrate: $34.4 \%$ & \\
\hline Wash water to the rougher spirals: $270 \mathrm{~m}^{3} / \mathrm{h}$ & \multirow{6}{*}{$\begin{array}{l}\text { Reduction of the wash water to the rougher: } \\
\text { Objective: Reduce losses of coarse iron oxide } \\
\text { particles in the roughers }\end{array}$} \\
\hline Rougher concentrate: $56.8 \% \mathrm{Fe}$ & \\
\hline Wash water to the cleaner spirals: $650 \mathrm{~m}^{3} / \mathrm{h}$ & \\
\hline Wash water to the re-cleaner spirals: $650 \mathrm{~m}^{3} / \mathrm{h}$ & \\
\hline Final Concentrate: $65.8 \% \mathrm{Fe}$ & \\
\hline Weight recovery to final concentrate: $35.6 \%$ & \\
\hline $\begin{array}{l}\text { Wash water to the rougher spirals: } 270 \mathrm{~m}^{3} / \mathrm{h} \\
\text { Rougher concentrate: } 56.8 \% \mathrm{Fe}\end{array}$ & \multirow{4}{*}{$\begin{array}{l}\text { Increase of the wash water to the cleaner and } \\
\text { re-cleaners: } \\
\text { Objective: Improve cleaning action of the } \\
\text { cleaners and re-cleaner spirals. }\end{array}$} \\
\hline $\begin{array}{l}\text { Wash water to the cleaner spirals: } 670 \mathrm{~m}^{3} / \mathrm{h} \\
\text { Wash water to the re-cleaner spirals: } 670 \mathrm{~m}^{3} / \mathrm{h}\end{array}$ & \\
\hline Final Concentrate: $66.1 \% \mathrm{Fe}$ & \\
\hline Weight recovery to final concentrate: $35.1 \%$ & \\
\hline
\end{tabular}

processing $100,000 \mathrm{t} / \mathrm{d}$ of ore. Also the simulation allows to anticipate the actions that need to be taken to bring the process back to the production of a concentrate of an acceptable quality.

\subsection{Simulation of a Modification to the Flowsheet of the Gravity Concentration Circuit}

The other option considered to increase the weight recovery to the final concentrate is to modify the circuit configuration by introducing a hydraulic classifier or fluidized-bed separator [18] [19] into the cleaning section of the circuit. A hydraulic classifier is a gravity concentration equipment that separates particles according to their weight (size and density), but that, unlike the spiral, can completely recover the coarse heavy particles. The principle of operation of a hydraulic classifier is shown in Figure 15. The slurry of water and particles enters the top of the classifier. The slurry is then exposed to an upward flow of water that entrains the light particles (e.g. quartz) to an overflow launder while the heavy particles (e.g. coarse and medium size hematite) settle and are recovered at the bottom of the hydraulic classifier as a cleaned concentrate. Depending on the operating conditions, a portion of the fine heavy minerals could be lost to the classifier overflow. The operation of the hydraulic classifier is controlled by the opening of the underflow valve that controls the density of the bed above the injection of teeter water and by the flow rate of teeter (see Figure 15) or fluidiza- 
tion water. The observed size recovery curves of iron oxide and quartz in a hydraulic classifier are shown in Figure 16. The position of the curves can be modulated by adjusting the fluidization water and the bed density as shown in Figure 16. Unlike what is observed for spirals, coarse hematite particles are

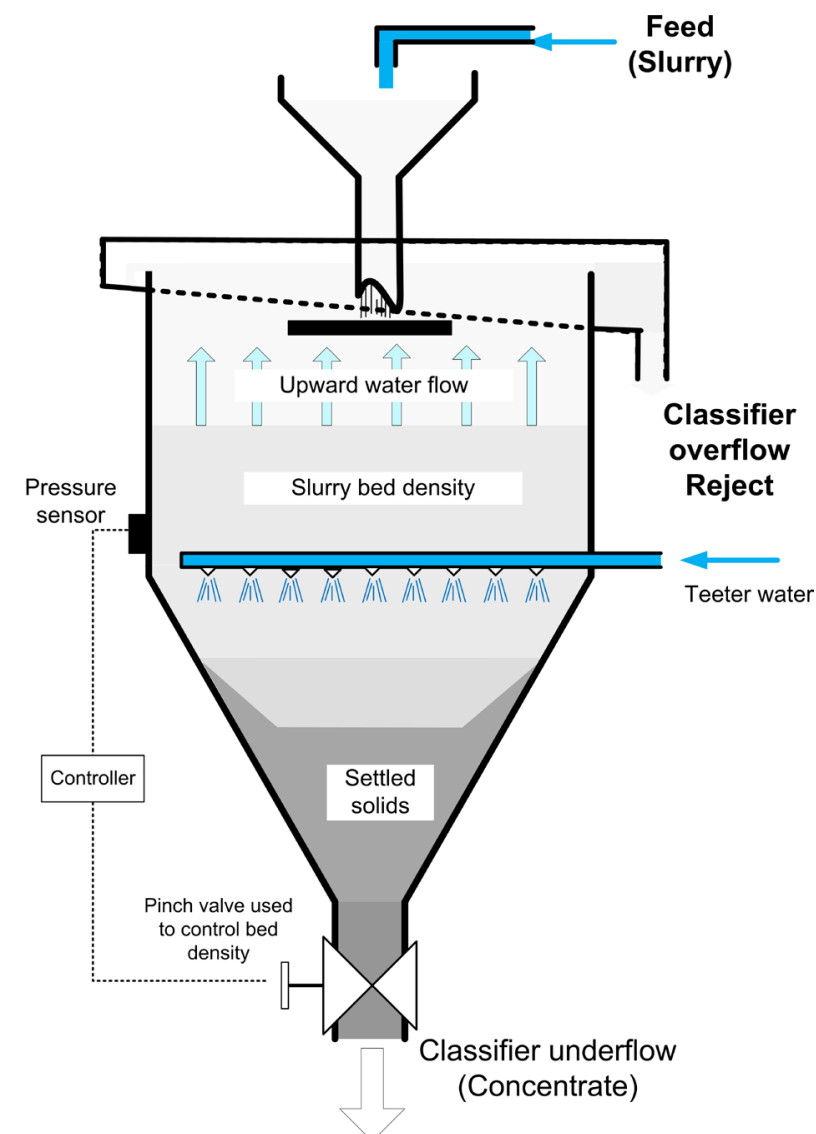

Figure 15. Hydraulic classifier (HC) [20].

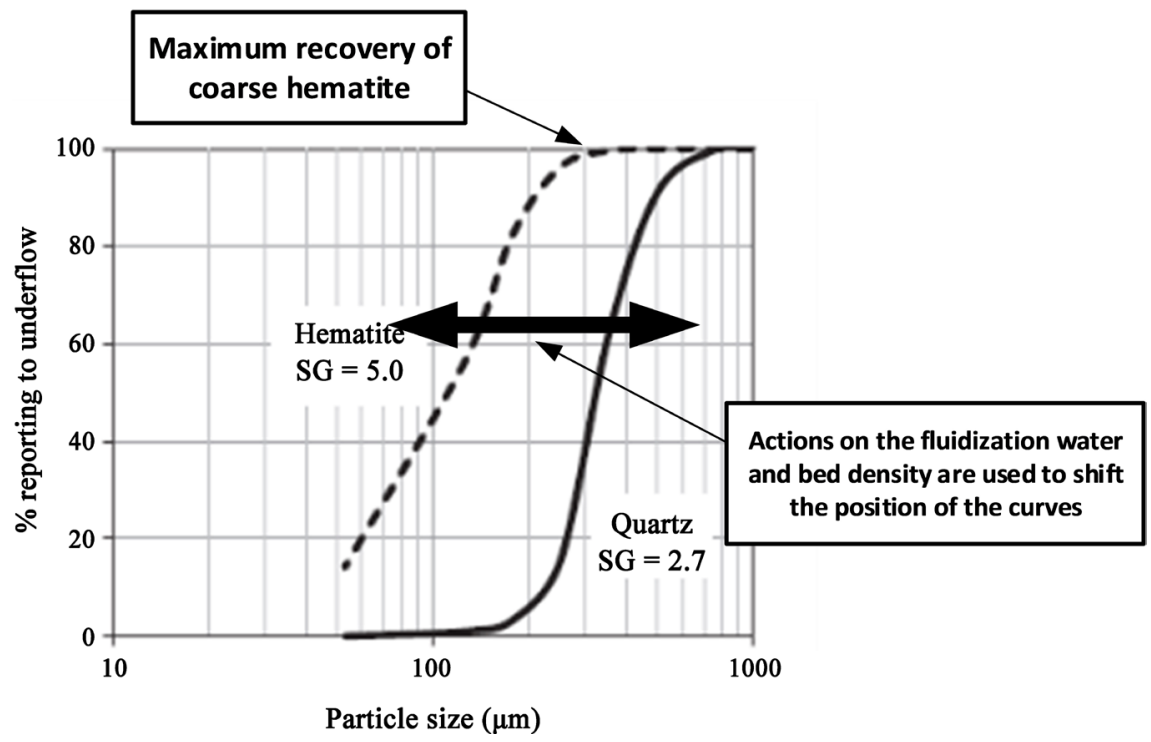

Figure 16. Size recovery curves for a hydraulic classifier (HC) [20]. 
fully recovered in the classifier underflow. Work is progressing toward the development of a phenomenological model for the hydraulic classifier and the model used here is a preliminary version that allows to manipulate the flow rate of teeter water and to predict the separation of hematite and quartz as a function of particle size [20].

The hydraulic classifier (HC) size recovery curve for hematite (Figure 16) shows that coarse $(>0.3 \mathrm{~mm})$ particles are fully recovered in the underflow of the hydraulic classifier, i.e. where it should be. Also, the separation of the quartz between the overflow (reject) and the underflow (concentrate) is better defined than it is for the spiral concentrator. A possible application of the HC would be to replace the cleaner-recleaner spirals to process the concentrate of the rougher spirals as a way to avoid losing coarse iron oxide particles in the middling and reject streams of the cleaner-recleaner spirals as observed for these spirals (see Figures 3-6). This circuit configuration is shown in Figure 17.

The other studied circuit modification uses the HC to process the middlings of the cleaner-re-cleaner spirals of the original circuit (Figure 2) in order to recover coarse hematite lost by these spirals instead of recycling them to the rougher spirals where they may not be recovered and lost to tailings. This second configuration is shown in Figure 18. The simulation should allow to verify if the iron content in the underflow of the $\mathrm{HC}$ is sufficiently high to be combined with the concentrate from the recleaner to give a mixture that assays more than $66 \%$ $\mathrm{Fe}$ at a weight recovery above $34 \%$. The reject streams from the cleaner/recleaner spirals and from the hydraulic classifier are combined to feed dewatering hydrocyclones that direct light particles and water to the overflow and ultimately to the plant tailings. The heavier solids (underflow) are recycled to the circuit feed to give the iron minerals another chance to be recovered.

\subsubsection{Simulation of the Use of the Hydraulic Classifier to Clean the Spiral Rougher Concentrate}

The simulator for the gravity concentration circuit was modified to incorporate

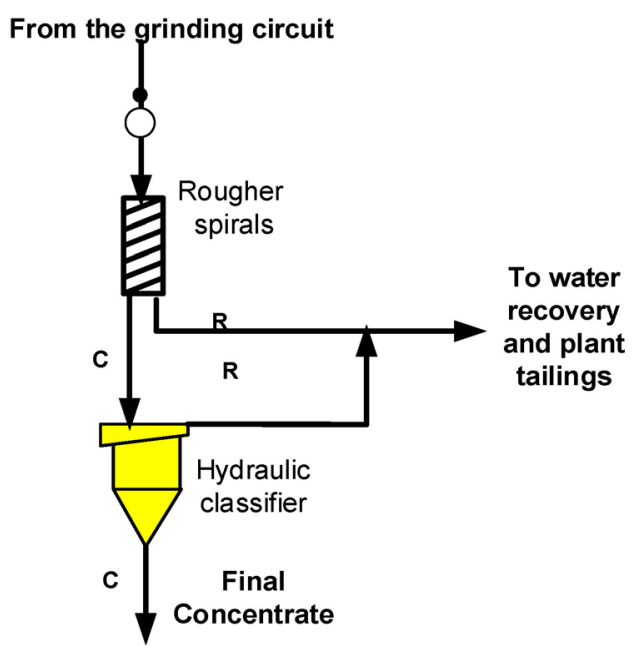

Figure 17. Cleaning the concentrate of the rougher spirals with a hydraulic classifier. 


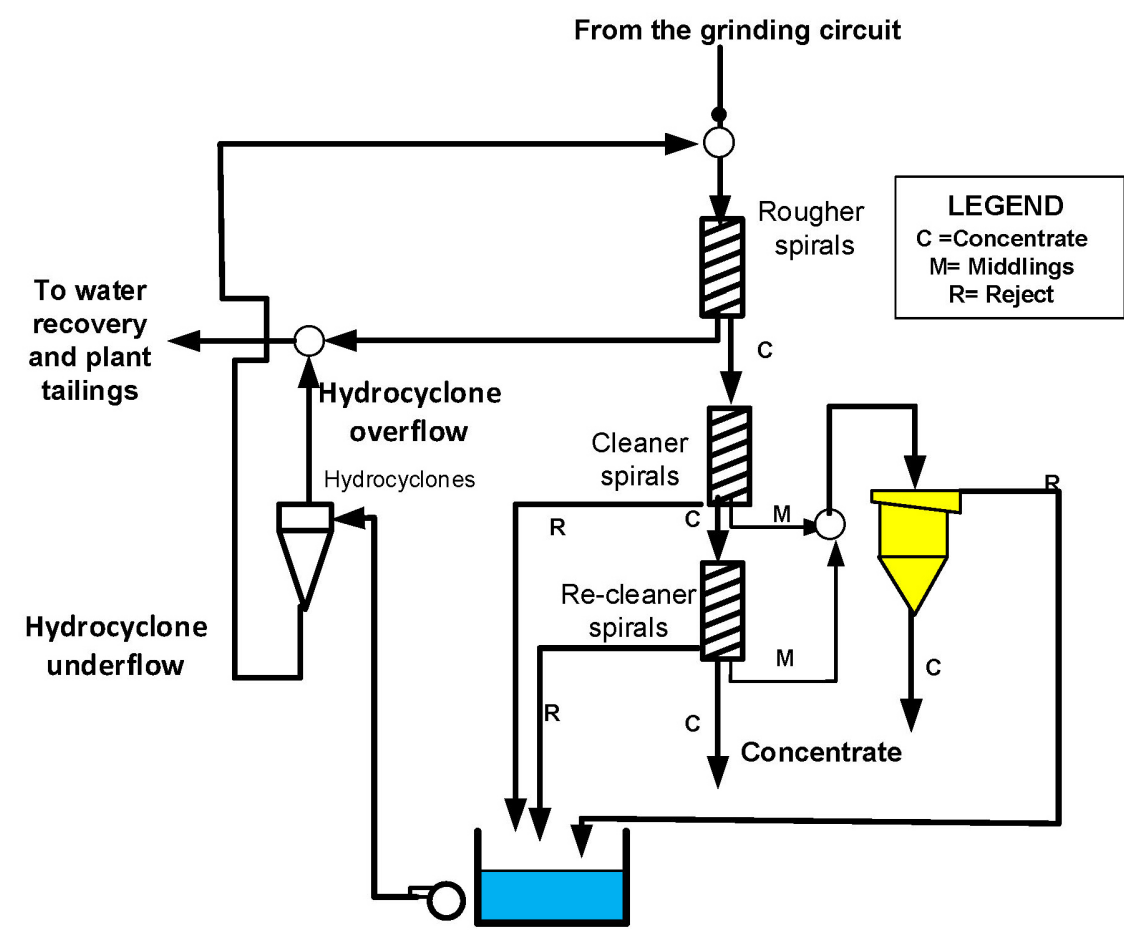

Figure 18. Scavenging the middling and reject of the cleaner/re-cleaner spirals with a hydraulic classifier.

a hydraulic classifier (HC) to process the rougher concentrate as shown by the screen capture of the program user's interface reproduced in Figure 19. The model for the rougher spirals is adjusted to mimic the plant operation and corresponds to the simulation carried out in the previous section $(\$ 4.1)$. The simulation of the $\mathrm{HC}$ is initially done by assuming a classifier of $1.2 \mathrm{~m} \times 1.2 \mathrm{~m}$ with a fluidization water flowrate $400 \mathrm{l} / \mathrm{min}$, which led to the results of Case A of Table 2. The predicted final concentrate grade of $64.9 \% \mathrm{Fe}$ is below the target of $66 \%$ imposing to operate the $\mathrm{HC}$ more aggressively by increasing the fluidization water to push more quartz to the overflow. The drawback of this action is the decrease in the weight recovery due to the entrainment of fine iron mineral particles to the $\mathrm{HC}$ overflow as shown by Cases B and C of Table 2. The target iron content of $66 \%$ is achieved at a weight recovery of $32.9 \%$ (Case C) which is low compared to the $34 \%$ - $35 \%$ obtained by using the original cleaner/recleaner spirals flowsheet (\$4.2.1). The circuit weight recovery can be increased by reducing the wash water to the rougher spirals to increase the weight recovery in the rougher spirals. The simulation shows that the $\mathrm{HC}$ is able to clean the lower rougher concentrate grade to the $66 \%$ Fe target with a weight recovery of $34.1 \%$ (Case D). The improved circuit weight recovery is achieved because the recovery in the rougher spirals is enhanced following the reduction of the wash water addition. The simulated HC partition curves for hematite and quartz at a water fluidization flowrate of $600 \mathrm{l} / \mathrm{min}$ are shown in Figure 20. About $50 \%$ of the hematite in particles of less than $0.3 \mathrm{~mm}$ are lost to the classifier reject which could be an incentive to process the $\mathrm{HC}$ reject stream (overflow) using another 


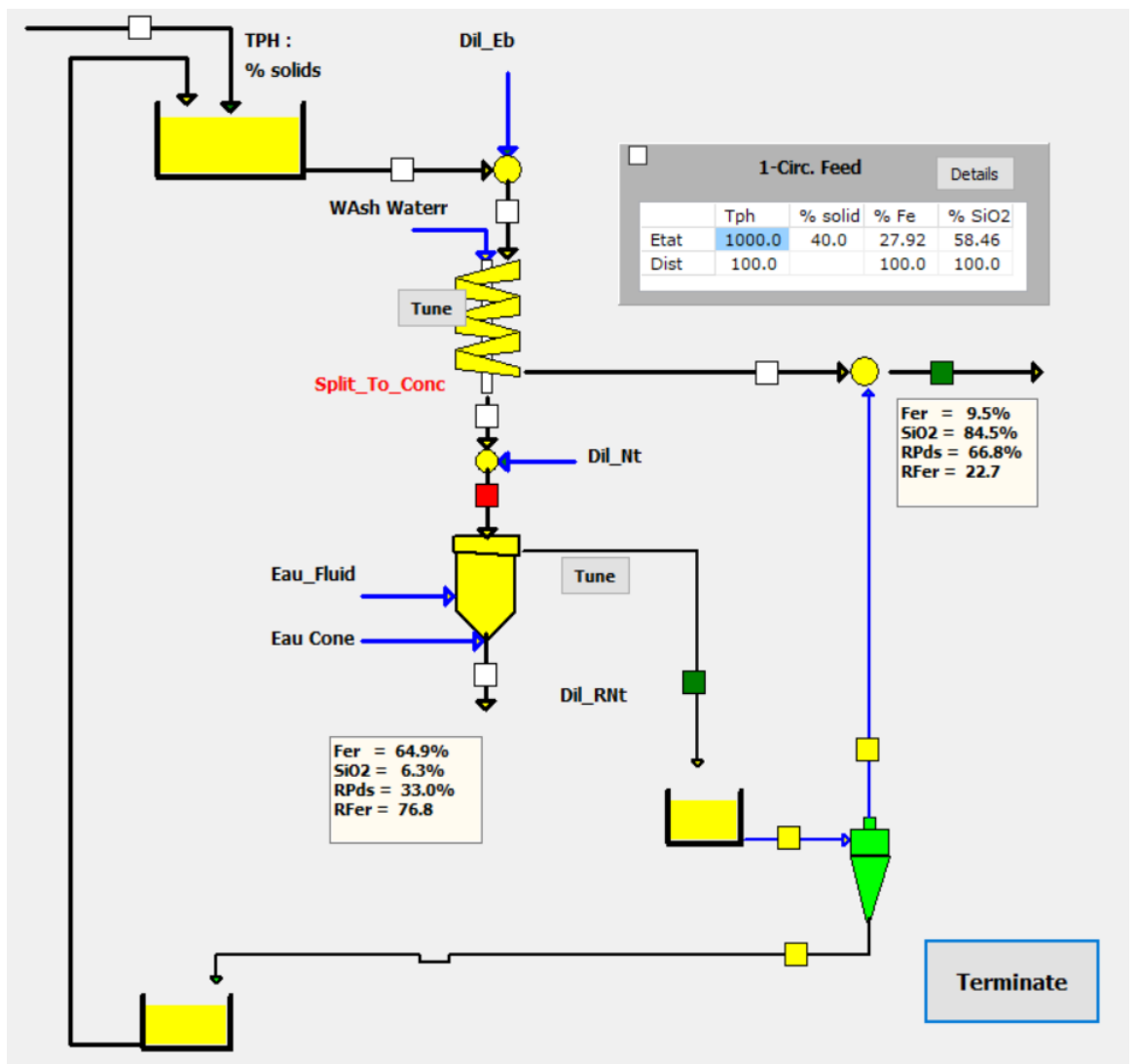

Figure 19. User's interface for the simulation of the gravity concentration circuit using an $\mathrm{HC}$ to clean the concentrate of the rougher spirals.

Table 2. Simulation study of the gravity circuit of Figure 19.

\begin{tabular}{cccccc}
\hline Case & $\begin{array}{c}\text { Fluidization } \\
\text { water } \\
(1 / \mathrm{min})\end{array}$ & $\begin{array}{c}\text { Weight } \\
\text { recovery } \\
(\%)\end{array}$ & $\begin{array}{c}\text { Final } \\
\text { concentrate } \\
\text { grade } \\
(\% \mathrm{Fe})\end{array}$ & $\begin{array}{c}\text { Rougher spiral } \\
\text { concentrate } \\
\text { grade } \\
(\% \mathrm{Fe})\end{array}$ & Note \\
\hline No HC & & 34.4 & 66.1 & 57.2 & Circuit with cleaner/recleaner spirals \\
$\mathrm{A}$ & 400 & 33.0 & 64.9 & 59.8 & Initial tuning of the rougher spirals \\
B & 500 & 32.9 & 66.0 & 59.8 & $\begin{array}{c}\text { Initial tuning of the rougher spirals } \\
\text { Initial tuning of the rougher spirals }\end{array}$ \\
C & 600 & 32.6 & 66.7 & 59.8 & $\begin{array}{c}\text { Reduced wash water to the rougher } \\
\text { spirals }\end{array}$ \\
\hline
\end{tabular}

gravity concentration device such as a spiral designed for fine particle processing [8] to recover some of this hematite. Results of parallel simulation run not shown here indicate that the configuration using a hydraulic classifier in replacement of the cleaner/recleaner spirals is less sensitive to variation in the circuit feed characteristics than the original circuit using cleaner/recleaner spirals. This result indicates that the configuration of Figure 15 may facilitate the operation of the circuit to maintain a final concentrate on the target grade. It was recently found that the configuration of Figure 15 has already been successfully 


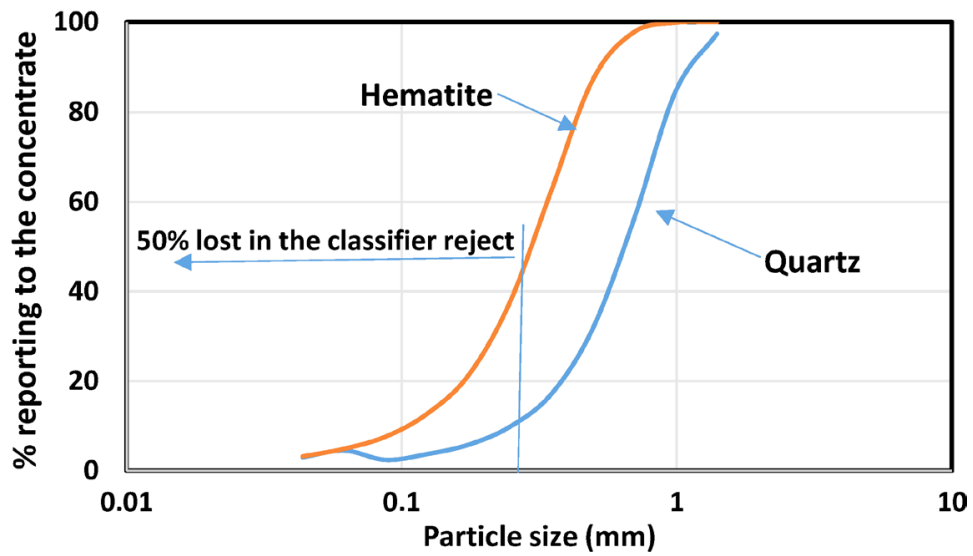

Figure 20. Simulated partition curves for hematite and quartz for the hydraulic classifier operated at a water fluidization rate of $600 \mathrm{l} / \mathrm{m}$ (Case D of Table 2).

implemented in a plant [11] which indirectly confirms the usefulness of simulation to study the advantage of a circuit configuration over another one.

\subsubsection{Simulation of the Use of the Hydraulic Classifier to Process the Middlings of the Cleaner/Recleaner Spirals}

The idea behind the circuit configuration of Figure 18 is to try to recover the coarse hematite particles that are lost in the cleaning spirals instead of circulating them back to the rougher where they may not be recovered. This configuration including the hydraulic classifier would be very difficult to test at a plant scale and very expensive to run in a pilot plant. However simulation provides a noise-free environment to test the idea and assess the limitations of the modified circuit configuration. The simulation results may thus help in deciding to continue the evaluation with full scale or pilot testing.

The initial simulation runs were conducted with the tuning used in section 4.1 to simulate the original circuit of Figure 2. Table 3 gives the iron content and weight recovery in the main streams of the circuit. Figure 21 shows the simulated flowsheet and indicates the stream numbers to facilitate the referencing to Table 3. In the initial tuning (without $\mathrm{HC}$ ) the final concentrate assays $66.1 \% \mathrm{Fe}$ with a weight recovery of $34.4 \%$. The initial simulation of the circuit with the hydraulic classifier to process the middlings of the cleaner/recleaner spirals yields a concentrate from the recleaner spirals assaying $66.3 \% \mathrm{Fe}$ at a weight recovery of $30.3 \%$. The lower recovery is due to the fact that the iron minerals lost in the middlings of the cleaner/recleaner spirals are not recycled back to the rougher spirals as it is the case for the original circuit, but are captured by the hydraulic classifier to produce a low grade concentrate assaying $59.1 \%$ Fe which represents $11.1 \%$ of the iron entering the circuit. The total weight recovery (recleaner concentrate + hydraulic classifier concentrate) for the modified circuit is $32.8 \%(30.3+2.5)$ which is well below the $34.4 \%$ recovery for the original circuit. The combination of the two concentrates would assay $65.8 \%$ Fe that is below the $66 \% \mathrm{Fe}$ target. The circuit configuration is therefore not viable unless it is possible to find the operating conditions of the spirals and hydraulic classifier that 


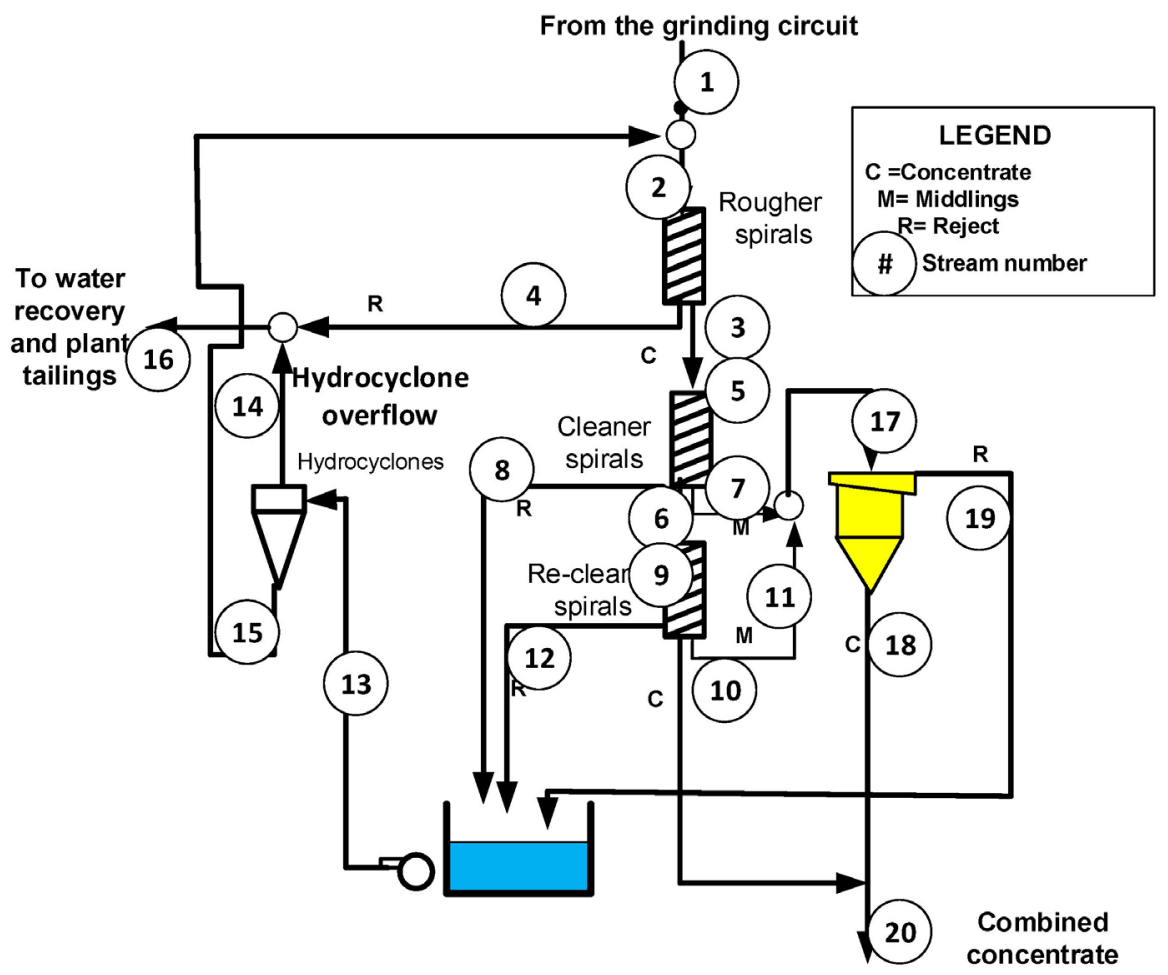

Figure 21. Corresponding numbers for the streams of Table 3.

allow the production of a global concentrate on the $66 \%$ Fe target. An adjustment to the fluidization water and to the bed density of the hydraulic classifier, as well as an increase of the wash water to the rougher and to the cleaner spirals allow the production of a combined HC and recleaner spirals concentrate assaying $65.6 \% \mathrm{Fe}$ at a total weight recovery of $35.4 \%$. Results of this simulation run are given in Table 3. It is likely that even better results can be obtained by adjusting the positions of the splitters of the cleaner/recleaner spirals, the HC bed density and fluidization water... This could obviously become the subject of a multi-variable optimization project considering the number of available manipulated variables (wash water to spirals, fluidization water and position of the splitters for the spirals) that can be used to maximize the weight recovery under the constraint of producing a final concentrate assaying $66 \% \mathrm{Fe}$.

In summary, even if it is anticipated that the previously studied configuration can be tuned to achieve the iron content constraint for the combined concentrate at an increased weight recovery and that the open configuration of the proposed circuit may facilitate process control, it is not recommended to use the hydraulic classifier as a scavenging equipment for the cleaner spirals, as the tuning of the circuit may be demanding during a full scale plant operation.

\subsection{Discussion}

This example illustrates the application of simulation to the optimization of the operation of a gravity concentration circuit, an approach that can substantially reduce the risk associated with the testing on a full scale process and reduce the 
Table 3. Simulation study of the gravity concentration circuit of Figure 18 .

\begin{tabular}{|c|c|c|c|c|c|c|c|}
\hline \multirow[t]{2}{*}{$\#$} & \multirow{2}{*}{ Stream } & \multicolumn{2}{|c|}{$\begin{array}{c}\text { Original circuit } \\
\text { No hydraulic classifier }\end{array}$} & \multicolumn{2}{|c|}{$\begin{array}{l}\text { Original circuit with. } \\
\text { hydr. Class. for scavenging } \\
\text { Initial Tuning }\end{array}$} & \multicolumn{2}{|c|}{$\begin{array}{l}\text { Original circuit with. } \\
\text { hydr. Class. for scavenging } \\
\text { Adjusted Tuning }\end{array}$} \\
\hline & & Fe Content (\%) & $\begin{array}{l}\text { Weight rec } \\
(\%)\end{array}$ & $\begin{array}{c}\text { Fe Content } \\
(\%)\end{array}$ & $\begin{array}{c}\text { Weight rec } \\
(\%)\end{array}$ & Fe Content (\%) & $\begin{array}{c}\text { Weight rec } \\
\text { (\%) }\end{array}$ \\
\hline 1 & Circuit feed & 27.9 & 100 & 27.9 & 100 & 27.9 & 100 \\
\hline 2 & Rougher feed & 26.7 & 111.5 & 27.6 & 110.2 & 27.5 & 109.2 \\
\hline 3 & Rougher conc. & 57.2 & 49.8 & 56.2 & 45.8 & 55.23 & 94.8 \\
\hline 4 & Rougher tails & 7.8 & 69.4 & 7.3 & 64.2 & 6.5 & 14.9 \\
\hline 5 & Cleaner feed & 57.2 & 49.8 & 56.2 & 45.8 & 55.23 & 94.8 \\
\hline 6 & Cleaner conc. & 63.4 & 39.7 & 63.2 & 35.8 & 63.1 & 81 \\
\hline 7 & Cleaner midd. & 29.9 & 7.7 & 28.1 & 7.2 & 28 & 7.3 \\
\hline 8 & Cleaner tails & 39.4 & 2.9 & 38.6 & 2.7 & 38.5 & 3.7 \\
\hline 9 & Releaner feed & 63.4 & 39.7 & 63.2 & 35.8 & 63.1 & 81 \\
\hline 10 & Recleaner conc. & 66.1 & 34.4 & 66.3 & 30.3 & 66.2 & 30.2 \\
\hline 11 & Releaner midd. & 47.9 & 5.1 & 47.9 & 4.3 & 47.8 & 7.4 \\
\hline 12 & Recleaner tails & 38.4 & 1.5 & 40.8 & 1.3 & 40.7 & 1.8 \\
\hline 13 & Hydrocyclone feed & 39.16 & 2.9 & 24.8 & 10.2 & 23.4 & 8.7 \\
\hline 14 & Hydrocyclone $\mathrm{O} / \mathrm{F}$ & 0.51 & 2.7 & 0.35 & 2.4 & 0.36 & 0.04 \\
\hline 15 & Hydrocyclone U/F & 39.6 & 2.9 & 24.9 & 10.2 & 23.5 & 8.7 \\
\hline 16 & Plant tails & 7.8 & 65.8 & 7.3 & 64.2 & 7.3 & 16.8 \\
\hline 17 & Hydraulic Classif feed & & & 35.5 & 11.6 & 35.4 & 14.7 \\
\hline 18 & Hydraulic Classif conc & & & 59.1 & 2.5 & 62.3 & 5.2 \\
\hline 19 & Hydraulic Classif tails & & & 15.9 & 6.3 & 13.8 & 3.2 \\
\hline 20 & Combined conc. & & & 65.8 & 32.8 & 65.6 & 35.4 \\
\hline
\end{tabular}

cost of piloting the process by allowing to rapidly screen different circuit configurations and tunings. Indeed if the simulation gives a taste of the difficulty associated with the operation of a circuit, it is likely that the operation of this circuit would be difficult in practice. It is obvious from the previous simulations that if a hydraulic classifier needs to be installed in an existing circuit, it would be preferable to use and operate the equipment for the cleaning of the concentrate from the rougher spirals rather than using it for scavenging the middlings of the cleaner/recleaner spirals.

While conducting the investigation it became rapidly obvious that it is important that the simulation tool should allow to modify the operating conditions of the plant, such as the addition of wash water to spirals or fluidization water to a hydraulic classifier. Indeed many commercial simulation tools for mineral processes ask the users to enter the values of model parameters for the equipment's rather than the state of their manipulated variables and this often demo- 
tivates the plant operators to regularly make use of these tools for process analysis and improvements. Unlike the numerous simulation studies that conclude significant improvement over the normal plant operating performances, this study shows that only a marginal improvement can be achieved through a modification to the circuit configuration implying capital expenditures. However when applied to a circuit processing 100,000 tons of ore per day, this marginal gain translates into a significant increase of revenues. Also the simulation study shows that achieving this marginal gain may require some major retuning and rethinking of the circuit operating strategies currently used.

\section{Conclusion}

The application of basic process analysis to two industrial iron ore concentration circuits shows that more than $10 \%$ of potentially recoverable coarse hematite is lost by the spirals used to recover the valuable mineral. Process analysis and simulation also show that an improvement in the recovery of this coarse hematite can be achieved by re-tuning the operating conditions of the plant spirals. Various circuit configurations with the introduction of a hydraulic classifier were also studied using simulation and results also show a marginal gain in recovery, in spite of the required Capex.

\section{Acknowledgements}

The authors acknowledge the technical and financial support of Arcelor-Mittal Mount Wright and of COREM. The authors are also grateful to the Quebec FQRNT for the grant provided to support the project.

\section{Conflicts of Interest}

The authors declare no conflicts of interest regarding the publication of this paper.

\section{References}

[1] Damjanovic, B. and Goode, J.R. (2000) Canadian Milling Practice, Special Vol. 49. Canadian Institute of Mining, Metallurgy and Petroleum, Montreal.

[2] Wills, B. (1992) Mineral Processing Technology: An Introduction to the Practical Aspects of Ore Treatment and Mineral Recovery. Pergamon Press, Oxford, New York, $855 \mathrm{p}$.

[3] Das, S.K., Godiwalla, K.M., Panda, L., Bhattacharya, K.K., Signh, R. and Mehrotra, S.P. (2007) Mathematical Modeling of Separation Characteristics of a Coal-Washing Spiral. International Journal of Mineral Processing, 84, 184-132. https://doi.org/10.1016/j.minpro.2007.05.007

[4] Tripathy, S.K. and Murthy, Y.R. (2012) Modelling and Optimization of Spiral Concentrator for Separation of Ultrafine Chromite. Powder Technology, 221, 387-394. https://doi.org/10.1016/j.powtec.2012.01.035

[5] Srivastava, M.P., Pan, S.K., Prasad, N. and Mishra, B.K. (2001) Characterization and Processing of Iron Fines of Kiriburu Deposit of India. International Journal of Mineral Processing, 61, 93-107. https://doi.org/10.1016/S0301-7516(00)00030-2 
[6] Sadeghi, M., Bazin, C. and Renaud, M. (2014) Effect of Wash Water on the Mineral Size Recovery Curves in a Spiral Concentrator Used for Iron Ore Processing. International Journal of Mineral Processing, 129, 22-26. https://doi.org/10.1016/j.minpro.2014.04.006

[7] Bazin, C., Sadeghi, M. and Renaud, M. (2016) An Operational Model for a Spiral Classifier. Minerals Engineering, 91, 74-85. https://doi.org/10.1016/j.mineng.2015.09.024

[8] Burt, R.O. (1984) Gravity Concentration Technology. Elsevier, Amsterdam, 336 p.

[9] Mishra, B.K. and Tripathy, A. (2010) A Preliminary Study of Particle Separation in Spiral Concentrators Using DEM. International Journal of Mineral Processing, 94, 192-195. https://doi.org/10.1016/j.minpro.2009.12.005

[10] Bazin, C., Sadeghi, M., Bourassa, M., Roy, P., Lavoie, F., Cataford, D., Rochefort, C. and Gosselin, C. (2014) Size Recovery Curves of Minerals in Industrial Spirals for Processing Iron Oxide Ores. Minerals Engineering, 65, 115-123. https://doi.org/10.1016/j.mineng.2014.05.012

[11] Lavoie, F. (2019) Bloom Lake Flowsheet Assessment, One Year into Operation. The CIM General Meeting, Montreal, May 2019, 1-14.

[12] Hodouin, D. and Everell, M.D. (1980) A Hierarchical Procedure for Adjustment and Material Balancing of Mineral Processes Data. International Journal of Mineral Processing, 7, 91-116. https://doi.org/10.1016/0301-7516(80)90002-2

[13] Hyma, D.B. and Meech, J.A. (1989) Preliminary Tests to Improve the Iron Recovery from the -212 Micron Fraction of New Spiral Feed at Quebec Cartier Mining Company. Minerals Engineering, 2, 481-488. https://doi.org/10.1016/0892-6875(89)90083-6

[14] Bazin, C., Payenzo, G.M., Desnoyers, M., Gosselin, C. and Chevalier, G. (2011) Analysis and Modelling of the Operation of a Hydraulic Classifier for Iron Ore Concentrate. Minerals Engineering Conferences: Physical Separation 2011, Falmouth, June 2011, 25-40.

[15] Holtham, P.N. (1992) Particle Transport in Gravity Concentrators and the Bagnold Effect. Mineral Engineering, 5, 205-221. https://doi.org/10.1016/0892-6875(92)90043-9

[16] Holtham, P.N. (1992) Primary and Secondary Fluid Velocities on Spiral Separators. Minerals Engineering, 5, 79-91. https://doi.org/10.1016/0892-6875(92)90007-V

[17] Flintoff, B.C., Plitt, L.R. and Turak, A.A. (1987) Cyclone Modelling: A Review of Present Technology. CIM Bulletin, 80, 39.

[18] Klein, B. and Bamber, A. (2019) Physical Separation. In: SME Mineral Processing Handbook, Society of Mining Engineer, Denver, Chapter 6.

[19] Das, A., Sarkar, B. and Mehrotra, B.P. (2008) Prediction of Separation Performance of Floatex Density Separator for Processing of Fine Coal Particules. International Journal of Mineral Processing, 91, 41-49. https://doi.org/10.1016/j.minpro.2008.11.004

[20] Payenzo, G.M., Bazin, C., Desnoyers, M., Gosselin, C. and Chevalier, G. (2012) The Use of Simulation for Process Diagnosis: Application to a Gravity Separator. International Journal of Mineral Processing, 104-105, 11-16.

https://doi.org/10.1016/j.minpro.2011.11.009 